\title{
Clinico-aetiological profile of onychomycosis at a tertiary care centre in northeast India
}

\author{
${\text { Bijayanti Devi }{ }^{1} \text {, Dilimpou Pamei }{ }^{2, *} \text {, Sanalembi Mutum }}^{3}$ \\ ${ }^{1}$ Professor, ${ }^{2,3}$ Resident, Dept. of Dermatology, Regional Institute of Medical Sciences (RIMS), Imphal, Manipur, India
}

*Corresponding Author:

Email: dilimpamei@gmail.com

\begin{abstract}
Onychomycosis (OM) represents nearly 50 percent of all nail disorders and accounts for about 30 percent of all superficial fungal infections of the skin. Often it becomes a nidus for recurrent superficial skin infections.

Aims and Objectives: To study the clinico- aetiological profile of onychomycosis and identify various predisposing factors.

Materials and Methods: A hospital-based, cross-sectional prospective study from October 2010 to March 2012 in Department of Dermatology, Venereology and Leprology in collaboration with Department of Microbiology at a tertiary hospital in Imphal, Manipur. Demographic profile, detailed history, risk factors, clinical examinations, investigations which consisted of direct microscopy with $10 \%$ potassium hydroxide $(\mathrm{KOH})$, culture in Sebouraud's dextrose agar (SDA), SDA incorporated with chloramphenicol $(0.05 \mathrm{mgs} / \mathrm{ml})$ and cyclohexamide $(0.5 \mathrm{mg} / \mathrm{ml})$ were taken.

Results: A total of 122 (54 male and 68 female) patients diagnosed with onychomycosis were included in this study. Maximum number of our patients (56.6\%) was between 21 and 40 years of age. Male to female ratio was 1:1.3. Housewives form the predominant group accounting for $41.9 \%$, followed by students $(28.7 \%)$ and farmer $(13.9 \%)$. Some of the predisposing factors associated were smoking (25.4\%), trauma (31.2\%), concomitant fungal infection (59\%) and family history of superficial mycosis $(16.4 \%)$. DLSO (82\%) was the commonest morphological pattern of OM, followed by TDO (9.8\%). Trichophyton sp (44.3\%) forms the commonest aetiological agent of OM. NDMs constituted $36.9 \%$ of the total nail cases in our study. Aspergillus sp (73.3\%) was the most common isolate among the nondermatophyte molds (NDM), followed by Mucor sp (11.1\%). Dermatophytes (45\%) were the commonest cause of DLSO, Candida sp were responsible for all the cases of PSO.

Conclusion: Dermatophytes are still the commonest cause of onychomycosis but NDMs and yeast can no longer be ignored as one of the causative organisms of OM.
\end{abstract}

Keywords: Onychomycosis (OMs), Dermatophytes non dermatophytic moulds (NDMs), Candida, Northeast India.

\section{Introduction}

Nails are one of the most fascinating and functionally as well as cosmetically important component of the skin. Fungal infection of nail or onychomycosis $(\mathrm{OM})$ represents nearly 50 percent of all nail disorders and accounts for about 30 percent of all superficial fungal infections of the skin. ${ }^{1,2}$ Its prevalence is estimated at 2 to 18 percent worldwide and 48 percent incidence by age $70 .^{3}$

Onychomycosis per se may be asymptomatic but poses serious concern to clinicians, as it often becomes a nidus for recurrent superficial skin infections. The destruction and disfigurement of nail plate can lead to self-consciousness and impairment in doing fine work. ${ }^{4}$ Psychosocial and emotional effects resulting from it are widespread. ${ }^{5}$

Recently there has been a worldwide increase in incidence of onychomycosis due to social, cultural, economical factors as well as introduction of several newer antifungal drugs. The evolving role of nondermatophytic molds has also added a new dimension. In India, less work has been done in this regard from Northeastern region as compared to other parts of the country. The study centre Imphal (Manipur) with an altitude of 790 metres above sea level, average humidity of $72 \%$ to $78 \%$, temperature of $15^{\circ} \mathrm{C}$ to $32^{\circ} \mathrm{C}$ during summer and monsoon seasons form very fertile ground for fungal growth and proliferation. ${ }^{1}$
Therefore, data from this study will help in better understanding of disease pattern in this part of the country.

\section{Aims and Objectives}

To study the clinico-aetiological profile of onychomycosis and identify various predisposing factors

\section{Materials and Methods}

Source of Data: A hospital-based, cross-sectional prospective study

Study Period: October 2010 to March 2012

Settings: Department of Dermatology, Venereology and Leprology in collaboration with Department of Microbiology in a tertiary hospital in Imphal, Manipur.

\section{Method of Data Collection}

Inclusion Criteria: A case of onychomycosis was defined as a person with any one of the following-

1. Specimen positive for fungal mycelia and spores or pseudohyphae by microscopic examination and culture positive for fungus or fungi.

2. Specimen positive for fungal mycelia and spores or pseudohyphae by microscopic examination but culture negative for fungus or fungi. 
3. Specimen negative for fungal mycelia and spores or pseudohyphae by microscopic examination but culture positive for fungus or fungi.

\section{Exclusion Criteria}

1. Patient on immunosuppressant, corticosteriod, systemic and/or topical antifungal in the last three months of the study

2. Patient diagnosed with collagen vascular disease or presence of cutaneous and/or nail lesions of psoriasis or lichen planus

Procedure: Prior consent was taken and datas were recorded in preset pro-forma that included demographic profile, detailed history, risk factors, clinical examinations, investigations which consisted of direct microscopy with $10 \%$ potassium hydroxide $(\mathrm{KOH})$, culture in Sebouraud's dextrose agar (SDA), SDA incorporated with chloramphenicol $(0.05 \mathrm{mgs} / \mathrm{ml})$ and cyclohexamide $(0.5 \mathrm{mg} / \mathrm{ml})$.

Specimen Collection and Processing: The suspected nails were cleaned with $70 \%$ alcohol and nail clippings were taken with a sterile scalpel blade and collected in a black coloured sterile paper. The screening of the samples (one piece of the specimen) was done by direct microscopy with $10 \%$ potassium hydroxide $(\mathrm{KOH})$.
Another piece of the specimen was cultured on each of the two isolation media: Sebouraud's dextrose agar (SDA) and SDA incorporated with chloramphenicol $(0.05 \mathrm{mgs} / \mathrm{ml})$ and cyclohexamide $(0.5 \mathrm{mg} / \mathrm{ml})$. The culture tubes were incubated at $25^{\circ} \mathrm{C}$ and $37^{\circ} \mathrm{C}$ and examined daily for three weeks.

Statistical Analysis: Done by SPSS software, version 16.0 for Windows. $P$ value was calculated using chisquare test and value of $<0.05$ was taken as statistically significant. Ethics committee approval from the institute was obtained.

\section{Result}

A total of 122 patients were included in the study. Ages varied from 14 to 74 years with mean of 35.32 \pm 13.9 years. Maximum number of patients $(n=69$; $56.6 \%$ ) were between 21 to 40 years of age followed by 41 to 60 years $(n=33 ; 27.0 \%)$ [Table 1]. Slight female preponderance was seen $(n=68 ; 55.7 \%)$ with male to female ratio of $1: 1.3$. Housewives formed the predominant group $(\mathrm{n}=50 ; 41.9 \%)$ followed by students $(\mathrm{n}=35 ; 28.7 \%)$ [Table 2].

Table 1: Distribution of onychomycosis by gender and age groups

\begin{tabular}{|c|c|c|c|}
\hline \multicolumn{2}{|c|}{ Parameters } & Number of case & $\%$ \\
\hline \multirow[t]{2}{*}{ Sex } & Male & 54 & 44.3 \\
\hline & Female & 68 & 55.7 \\
\hline \multicolumn{2}{|l|}{ Total } & 122 & 100.0 \\
\hline \multirow[t]{4}{*}{ Age (in years) } & $<20$ & 13 & 10.7 \\
\hline & $21-40$ & 69 & 56.6 \\
\hline & $41-60$ & 33 & 27.0 \\
\hline & $61-80$ & 7 & 5.7 \\
\hline \multicolumn{2}{|l|}{ Total } & 122 & 100.0 \\
\hline
\end{tabular}

Table 2: Occupation-wise distribution of the patients

\begin{tabular}{|l|c|c|}
\hline \multicolumn{1}{|c|}{ Occupation } & Number of case & $\mathbf{\%}$ \\
\hline Student & 35 & 28.7 \\
\hline Housewife & 50 & 41.0 \\
\hline Manual labourer & 5 & 4.1 \\
\hline Farmer & 17 & 13.9 \\
\hline Sedentary worker & 8 & 6.6 \\
\hline Army personnel & 6 & 4.9 \\
\hline Others & 1 & 0.8 \\
\hline Total & 122 & 100 \\
\hline
\end{tabular}

Bilateral nail involvement was common $(n=67$; $54.9 \%)$ with fingernails $(\mathrm{n}=76 ; 62.3 \%)$ more frequently involved than toenails $(\mathrm{n}=28 ; 22.9 \%)$ in both males and females. Fingernail infection was more frequent in female (46/76) while toenail infection in males (17/28). $59 \%(\mathrm{n}=72)$ had other concomitant fungal infections. Chronic paronychia $(\mathrm{n}=39 ; 54.2 \%)$ was the most commonly associated fungal infection followed by tinea pedis $(\mathrm{n}=10 ; 13.9 \%)$.
Of the five clinical types of onychomycosis, DLSO was the most common $(\mathrm{n}=100 ; 82 \%)$ while WSO $(\mathrm{n}=2$; $1.6 \%$ ) was the least frequent [Table 3]. All the patients with PSO $(\mathrm{n}=3 ; 2.5 \%)$ were immunocompetent and negative for HIV-serological test (ELISA). 
Table 3: Frequency of various clinical patterns of onychomycosis (gender)

\begin{tabular}{|l|c|c|c|c|}
\hline \multicolumn{1}{|c|}{ Clinical pattern } & Male & Female & Total & \% \\
\hline DLSO & 39 & 61 & 100 & 82 \\
\hline PSO & 1 & 2 & 3 & 2.5 \\
\hline WSO & 2 & 0 & 2 & 1.6 \\
\hline EO & 4 & 1 & 5 & 4.1 \\
\hline TDO & 8 & 4 & 12 & 9.8 \\
\hline Total & 54 & 68 & 122 & 100.0 \\
\hline
\end{tabular}

Table 4: Various clinical patterns according to occupation

\begin{tabular}{|l|c|c|c|c|c|c|}
\hline \multirow{2}{*}{ Occupation } & \multicolumn{5}{|c|}{ Clinical type of onychomycosis } & \multirow{2}{*}{ Total (\%) } \\
\cline { 2 - 5 } & DLSO (\%) & PSO (\%) & WSO (\%) & EO (\%) & TDO (\%) & \\
\hline Students & $26(74.3)$ & $0(0)$ & $2(5.7)$ & $1(2.9)$ & $6(17.1)$ & $35(100)$ \\
\hline Housewives & $46(92)$ & $1(2)$ & $0(0)$ & $1(2)$ & $2(4)$ & $50(100)$ \\
\hline Manual labourer & $1(20)$ & $1(20)$ & $0(0)$ & $2(40)$ & $1(20)$ & $5(100)$ \\
\hline Farmer & $14(82.3)$ & $1(5.9)$ & $0(0)$ & $1(5.9)$ & $1(5.9)$ & $17(100)$ \\
\hline Sedentary workers & $6(75)$ & $0(0)$ & $0(0)$ & $0(0)$ & $2(25)$ & $8(100)$ \\
\hline Army personnel & $6(100)$ & $0(0)$ & $0(0)$ & $0(0)$ & $0(0)$ & $6(100)$ \\
\hline Others & $1(100)$ & $0(0)$ & $0(0)$ & $0(0)$ & $0(0)$ & $1(100)$ \\
\hline Total & $100(82)$ & $3(2.5)$ & $2(1.6)$ & $5(4.1)$ & $12(9.8)$ & $122(100)$ \\
\hline
\end{tabular}

Table 5: Sex distribution and fungal culture isolate in the study group

\begin{tabular}{|c|c|c|c|c|c|c|}
\hline 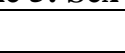 & Paramet & & Number of case & Male & Female & $\%$ \\
\hline Culture & & Trichophyton sp & 54 & 36 & 18 & \\
\hline & & Epidermophyton $\mathrm{sp}$ & 0 & 0 & 0 & 44.3 \\
\hline & & Microsporium sp & 0 & 0 & 0 & \\
\hline & Candida species & & 13 & 2 & 11 & 10.6 \\
\hline & Non-dermatophytic & Aspergillus sp & 33 & 9 & 24 & \\
\hline & molds (NDM) & Mucor sp & 5 & 2 & 3 & \\
\hline & & Rhizopus sp & 2 & 0 & 2 & \\
\hline & & Acremonium sp & 1 & 0 & 1 & 360 \\
\hline & & Curvularia sp & 2 & 1 & 1 & 30.9 \\
\hline & & Chrysosporium sp & 1 & 0 & 1 & \\
\hline & & Alternaria sp & 1 & 1 & 0 & \\
\hline & Total & & 45 & 13 & 32 & \\
\hline & Mixed growth & $\begin{array}{l}\text { Trichophyton } \mathrm{sp}+ \\
\text { Aspergillus sp }\end{array}$ & 3 & 0 & 3 & \\
\hline & & $\begin{array}{l}\text { Candida } \mathrm{sp}+ \\
\text { Aspergillus sp }\end{array}$ & 2 & 2 & 0 & 8.2 \\
\hline & & $\begin{array}{l}\text { Trichophyton sp + } \\
\text { Candida sp + NDM }\end{array}$ & 5 & 1 & 4 & \\
\hline & Total & & 10 & 3 & 7 & \\
\hline Grand to & & & 122 & 54 & 68 & 100.00 \\
\hline
\end{tabular}

Dermatophytes were the most commonly isolated fungi $(\mathrm{n}=54 ; 44.3 \%)$ followed by non-dermatophytic molds $(n=45 ; 36.9 \%)$ and yeasts $(n=13 ; 10.6 \%)$. Mixed fungal infections were isolated from $8.2 \%$. 


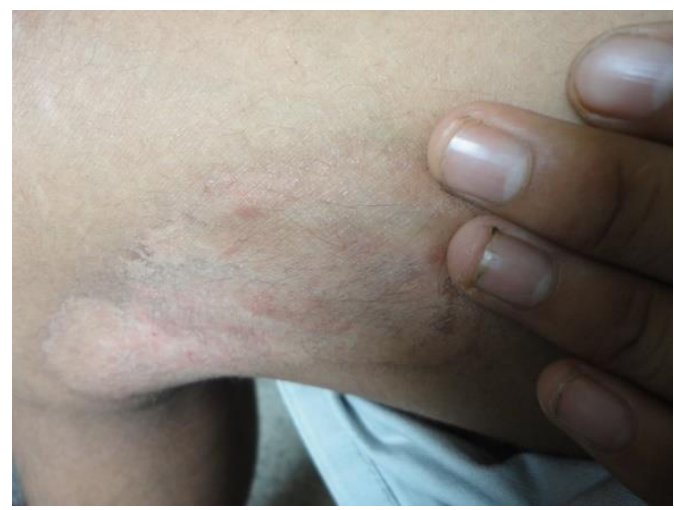

Fig. 2: DLSO of the left ring finger with tinea corporis

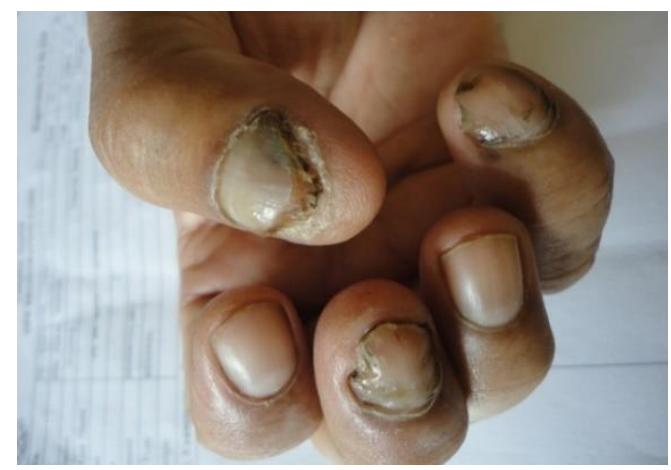

Fig. 3: DLSO of the right finger nails

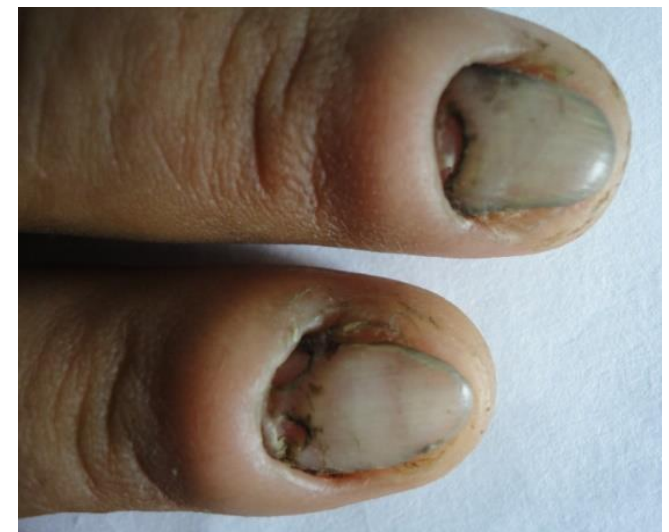

Fig 4: PSO of the right finger nails

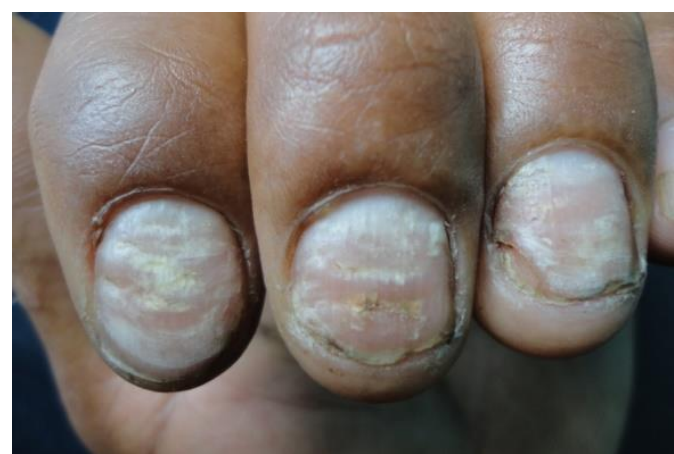

Fig. 5: WSO of the left fingernails

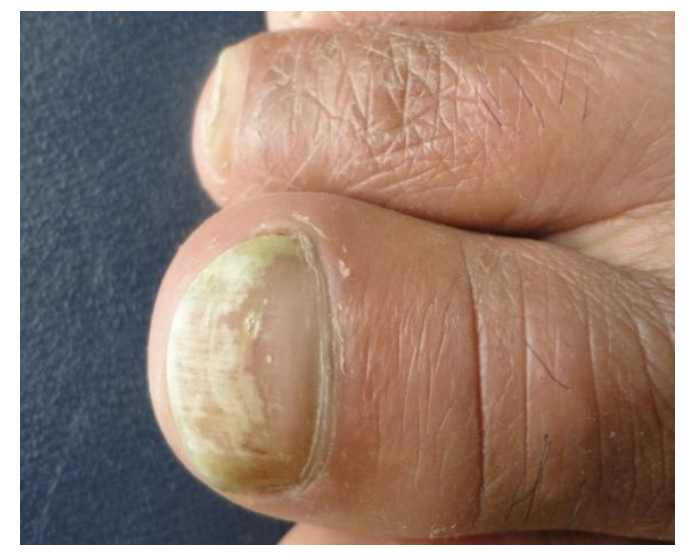

Fig. 6: EO of the right toenails

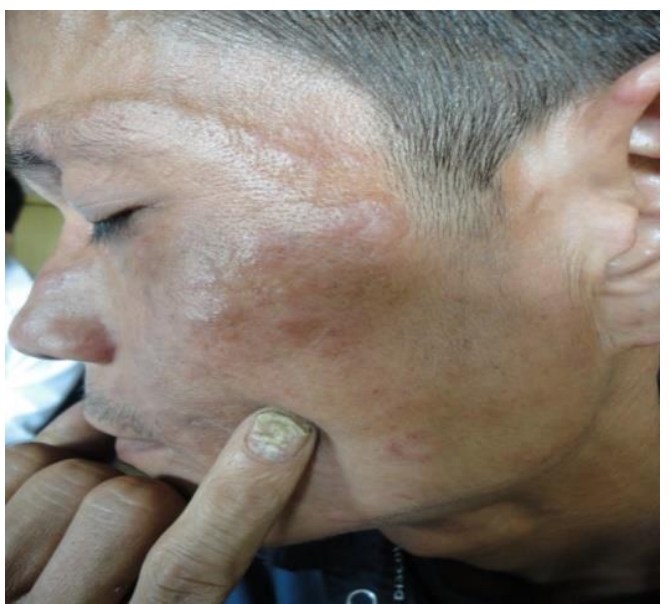

Fig. 7: SWO of the left fingernail associated with tinea faciei

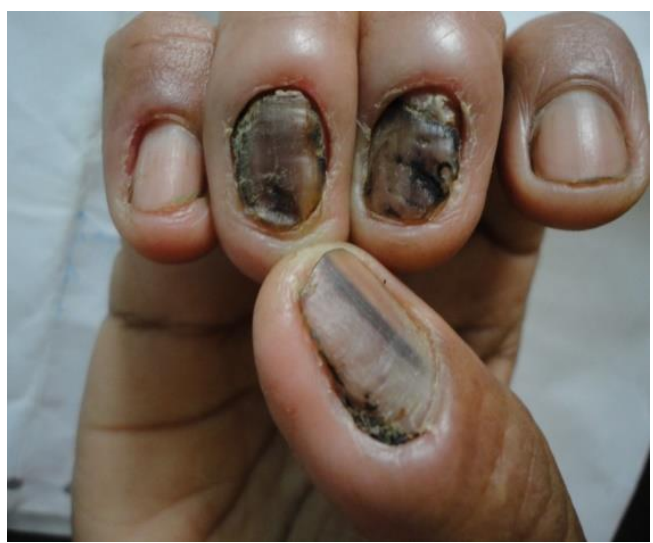

Fig. 8: TDO of the left fingernails caused by Trichophyton sp 
Table 6: Clinical patterns of onychomycosis and etiologic agents isolated

\begin{tabular}{|c|c|c|c|}
\hline \multicolumn{2}{|c|}{ Parameters } & Number of case (\%) & $\%$ \\
\hline \multirow[t]{4}{*}{ DLSO } & Dermatophytes & $45(45)$ & \multirow{5}{*}{82} \\
\hline & Candida species & $10(10)$ & \\
\hline & Nondermatophytic molds (NDM) & $38(38)$ & \\
\hline & Mixed growth & $7(7)$ & \\
\hline \multicolumn{2}{|l|}{ Total } & 100 & \\
\hline \multirow[t]{4}{*}{ PSO } & Dermatophytes & $0(0.0)$ & \multirow{5}{*}{2.5} \\
\hline & Candida species & $3(100)$ & \\
\hline & Nondermatophytic molds (NDM) & $0(0.0)$ & \\
\hline & Mixed growth & $0(0.0)$ & \\
\hline \multicolumn{2}{|l|}{ Total } & 3 & \\
\hline \multirow[t]{4}{*}{ WSO } & Dermatophytes & $2(100)$ & \multirow{5}{*}{1.6} \\
\hline & Candida species & $0(0.0)$ & \\
\hline & Nondermatophytic molds (NDM) & $0(0.0)$ & \\
\hline & Mixed growth & $0(0.0)$ & \\
\hline \multicolumn{2}{|l|}{ Total } & 2 & \\
\hline \multirow[t]{4}{*}{ EO } & Dermatophytes & $3(60)$ & \multirow{5}{*}{4.1} \\
\hline & Candida species & $0(0.0)$ & \\
\hline & Nondermatophytic molds (NDM) & $0(0.0)$ & \\
\hline & Mixed growth & $2(40)$ & \\
\hline \multicolumn{2}{|l|}{ Total } & 5 & \\
\hline \multirow[t]{4}{*}{ TDO } & Dermatophytes & $4(33.3)$ & \multirow{5}{*}{9.8} \\
\hline & Candida species & $0(0.0)$ & \\
\hline & Nondermatophytic molds (NDMs) & $7(58.3)$ & \\
\hline & Mixed growth & $1(8.4)$ & \\
\hline \multicolumn{2}{|l|}{ Total } & 12 & \\
\hline \multicolumn{2}{|c|}{ Grand Total } & 122 & 100.0 \\
\hline
\end{tabular}

Table 7: Comparative analysis of studies from different parts of India

\begin{tabular}{|l|c|c|c|c|c|}
\hline \multicolumn{1}{|c|}{ Features } & $\begin{array}{c}\text { Bijayanti et al. } \\
\text { (Imphal)2012 }\end{array}$ & $\begin{array}{c}\text { Lone et al. }{ }^{\mathbf{1 4}} \\
\text { (Kashmir)2013 }\end{array}$ & $\begin{array}{c}\text { Beena et al. } \mathbf{.}^{\mathbf{3}} \\
\text { (Bangalore)2013 }\end{array}$ & $\begin{array}{c}\text { Iqbal et al. } .^{\mathbf{1 1}} \\
\text { (Mumbai)2017 }\end{array}$ & $\begin{array}{c}\text { Ashokan et al. } \\
\text { (Chennai)2017 }\end{array}$ \\
\hline Age (years) & $21-40$ & $21-30$ & $21-40$ & $20-40$ & $20-40$ \\
\hline Gender & F > M & M > F & F > M & M > F & F>M \\
\hline Occupation & Housewife & - & Housewife & $\begin{array}{c}\text { Sedentary } \\
\text { workers }\end{array}$ & Active workers \\
\hline Finger/toes & Finger > Toe & Finger > Toe & Toe > Finger & Finger > Toe & Finger = Toe \\
\hline $\begin{array}{l}\text { M.c clinical } \\
\text { type }\end{array}$ & DLSO & DLSO & DLSO & - & DLSO \\
\hline M.c isolate & Dermatophytes & Dermatophytes & Dermatophytes & Dermatophytes & NDMs \\
\hline NDMs & $36.9 \%$ & $31.66 \%$ & $47.4 \%$ & $26.7 \%$ & $58.1 \%$ \\
\hline
\end{tabular}

\section{Discussion}

Onychomycosis affects all age groups. In this study, majority $(56.6 \%)$ were between $21-40$ years and least $(5.7 \%)$ above 61 years which were in concordance with most studies. ${ }^{1,11-14}$ The low prevalence in children is attributed to the difference in nail plate structure, lack of cumulative trauma and increased growth rate of nail plate with subsequent elimination of fungus. Increased participation in physical activity, more exposure to wet work, shoe wearing habit, early marriage leading to new household responsibilities, aesthetic concerns could be some of the contributing factors for increased prevalence in the 21-40 years age group.
In our study, onychomycosis was found to be more common in females $(55.7 \%)$ than males $(44.3 \%)$ similar to the observation reported by Usharani $\mathrm{M}$ et al. ${ }^{1}$ Domestic activity involving wet work associated with constant trauma to the nails could probably explain the slightly higher prevalence among women. ${ }^{12,13}$

Housewives form the predominant group accounting for $41.9 \%$, followed by students $(28.7 \%)$ and farmer (13.9\%). In $31.2 \%$ of the patient, history of preceding trauma was present. Trauma and smoking have also been attributed as important predisposing factors. ${ }^{2}$ High proportion of toenail involvement may be due to occlusive footwear which was similarly observed by Iqbal et al. ${ }^{11}$ 
Fingernails were exclusively involved in $62.3 \%$, toe nails in $22.9 \%$, both finger and toe nails in $14.8 \%$. This study highlights that fingernails alone are involved more commonly than toenails which is in concordance with other Indian studies. ${ }^{11,14}$ Increased incidence of occupation related trauma or because finger nail infection is more visually provoking could be the reason for high incidence. Open footwear and lesser concern for appearance of feet and toenails in the population resulting in lower reporting of toenail infections may explain for low incidence.

Higher incidence of fingernail affection were seen in females $(60.5 \%)$, while toenail infections were more observed in males (60.7\%). These findings are consistent with various other studies that attributed the higher incidence of fingernail infections in females to the fact that they commonly do more domestic chores such as washing dishes, laundry and handling foodstuffs than males reflecting the greater burden of wet work done by females. ${ }^{12,13}$ While high incidence of toenail infection in males may be because of increased exposure to outdoors with greater physical activity and more prone to trauma.

Presence of coexisting fungal infection in other parts of the body was noted in 100 patients $(82 \%)$. Amongst them chronic paronychia was the commonest followed by Tinea pedis, Tinea corporis, Tinea cruris and Tinea manuum. Neupane $\mathrm{S}$ et $\mathrm{al}^{2}$ reported that Tinea pedis was the commonest concomitant fungal infection.

Of the five clinical types of onychomycosis, DLSO was the most common clinical type observed in the present study seen in 100 (82\%) patients which is comparable to the findings of other authors, ${ }^{2,12-14}$

$\mathrm{KOH}$ smear examination of nail material under microscope was positive for fungal filaments in 15 $(12.3 \%)$ patients.

Of the organisms identified from all nail samples, dermatophytes were the most commonly isolated fungi (44.3\%) which was similar to most of the studies. ${ }^{1,11,13,14}$ In some studies ${ }^{12,15}$ NDMs were reported to be the commonest isolate followed by dermatophytes and yeast. Traditionally, yeasts and molds were considered exclusively as contaminating fungi or secondary pathogens that affected only the nails that had a history of trauma or disease. These so-called 'contaminants' now referred to collectively as NDMs significantly constituted about $36.9 \%$

In the past, mixed (more than one type of fungus within an infected nail) infections went largely unrecognized because the tendency has been to ignore the nondermatophytes, whenever a dermatophyte was present. A number of studies have clinically evaluated this incidence which ranged from almost 0 to $11 \% .{ }^{20} \mathrm{In}$ $10(8.2 \%)$ patients, mixed fungal infections were present. The most common being combination of Trichophyton sp, Candida sp and Aspergillus sp. (5 patients), followed by Trichophyton and Aspergillus combination (3 patients). Candida and Aspergillus sp combination was observed in 2 patients. Mixed fungal infections were higher in females then in males.

\section{Conclusion}

This study reveals that pathogens involved in onychomycosis vary according to geographical area thereby affecting clinical presentations. Dermatophytes was the most common isolate although role of NDMs and mixed fungal infections needs to be emphasised in this part of the country.

\section{Financial Support and Sponsorship: Nil.}

\section{Conflicts of Interest: Nil}

\section{References}

1. Usharani M, Bijayanti DT, Pratita DP. A study of onychomycosis in dystrophic nails. J Med Soc. 2001;15(2):31-2.

2. Neupane S, Pokhre DB, Pokhrel BM. Onychomycosis: A clinico-epidemiological study. Nepal Med Coll J. 2009; 11(2):92-5.

3. Nelson MM, Martin AG, Heffernan MP. Superficial Fungal Infections: Dermatophytosis, Onychomycosis, Tinea nigra, Piedra. In: Freedberg IM, Eisen AZ, Wolff K, Austen KF, Goldsmith LA, Stephen IK, editors. Fitzpatrick's Dermatology in General Medicine. 6th Ed. New York: Mc Graw- Hill Medical Publishing Division, 2003:1989-2005.

4. Mashkoor A, Sanjay G, Satish G. A clinico-mycological study of onychomycosis. Egyptian Dermatology Online Journal. 2010;6(1):4.

5. Lubeck DP. Measuring health related quality of life in onychomycosis. J Am Acad Dermatol. 1998;38(5 pt3):648.

6. Tasic S, Stojanovic S, Poljacki M, Klinicki ZKVB, Klinicki C, Novi S et al. Etiopthogenesis, Clinical picture and diagnosis of onychmycoses. Med Pregl. 2001;54 (12):45-51

7. Grover C, Khurana A. Onychomycosis: Newer insight in pathogenesis and diagnosis. Indian J Dermatol Venereol Leprol. 2012;78:263-70.

8. Ainsworth GC and Sussman AS: The Fungi, Lincoln LIN, United Kingdom, 1965; p 4.

9. Dey NC, Grueber HLE, Dey TK: Medical Mycology, $2^{\text {nd }}$ Ed. Allied Agency, Calcutta, 1973; p3-4.

10. Rippon JW. Medical mycology. 3rd Ed. Philadelphia, London: WB Saunders Company; 1974.

11. Igbal AF, Mahesh TU, Mukesh BS, Rachita D, Meghna P. A clinico-mycological study of onychomycosis at a tertiary care center. Asian Journal of Medical Sciences. 2017;8(1):48-57.

12. Ashokan C, Bubna AK, Sankarasubramanium A, Veeraraghavan M, Rangarajan S, Swaminathan A. A clinicomycological study of onychomycosis at a tertiary health- care center in Chennai. Muller J Med Sci Res. 2017;8:74-81.

13. Beena, Sreeja S, Bhavana MV, Babu PRS. Onychomycosis: prevalence and its etiology in a tertiary care hospital, South India. Int J Health Sci Res. 2013;3(10):81-85.

14. Lone B, Bashir D, Ahmad S, Syed A, Khurshid S. A study on clinico- mycological profile, aetiological agents and diagnosis of onychomycosis at a government medical 
college hospital in Kashmir. Journal of Clinical and Diagnostic Research. 2013;7(9):1983-1985.

15. Efuntoye MO, Sobowale AA, Mabekoje OO, Agu GC. Onychomycosis among rural farmers in a southwestern part of Nigeria. Egyptian Dermatology Online Journal. 2011;7(1):4

16. Sanjiv A, Shalini M, Charoo H. Etiological Agents of Onychomycosis from a Tertiary Care Hospital in Central Delhi, India. Indian Journal of Fundamental and Applied Life Sciences. 2011;1(2):11-4.

17. Kaur R, Kashyap B, Bhalla P. OnychomycosisEpidemiology, diagnosis and management. Ind J Med Micro. 2008;26(2):108-16.

18. Kaur R, Kashyap B, Bhalla P. A five-year survey of onychomycosis in New Delhi, India: Epidemiological and laboratory aspects. Indian J Dermatol. 2007;52:39-42.
19. Grover S. Clinico-mycological evaluation of onychomycosis at Bangalore and Jorhat. Indian J Dermatol Venereol Leprol. 2003;69:284-6.

20. Greer DL. Evolving role of nondermatophytes in onychomycosis. Int J Dermatol. 1995;34:521.

How to cite this article: Devi B, Pamei D, Mutum S. Clinico-aetiological profile of onychomycosis at a tertiary care centre in northeast India. Ind J Clin Exp Dermatol. 2018;4(3):205-211. 